\title{
SOPHIA
}

PEER REVIEW JOURNAL

CROSSING BORDERS, SHIFTING BOUNDARIES - PHOTOGRAPHY AND ARCHITECTURE

ISSN: 2183-8976 [PRINT] 2183-9468 [ONLINE]

Volume 2, Issue 1| Publication year: 2017

DOI 10.24840/2183-8976_2017-0002_0001_04

(c) SCOPIO EDITIONS

HOMEPAGE: HTTPS://WWW.SOPHIAJOURNAL.NET

\section{RE-INTERPRETING KIDDER SMITH'S ITALY BUILDS: CROSSOVERS BETWEEN PHOTOGRAPHY AND ARCHITECTURE}

Angelo Maggi

\begin{abstract}
George Everard Kidder Smith's book Italy Builds. Its modern architecture and native inheritances a collection of astonishing architectural photographs, data and critical comment upon the traditional and modern architecture. The many forms of visual narratives adopted by the author become a valuable index to the kind of building that the young mid-twentieth-century architect was prepared to see when he travelled Italy. Trained as an architect and, like many of his generation, using the camera as a tool of analysis and memory, Kidder Smith knew a certain amount of history but by no means considered himself an historian. He thus simply records what has interested him in the architecture of the past and present, and the photographs and explanatory text directly reveal how he has seen it. His eyes go first toward the primitive: the solid, earth-heavy shapes of masonry, the panels of brickwork, the skeletons of wood, the directly functional types, the solemn personification of human qualities in the landscape. When Kidder Smith turns to contemporary Italian architecture he consequently develops new standards of judgments. He encapsulates in his photographs the great range of Italy's modernist experience, always elegant, and usually with an intelligent touch. The paper will focus on the wake of the success between architectural photography and personal architecture criticism as a new creative processes which brought to light new ways of understanding both fields.
\end{abstract}

Keywords: Kidder Smith, Italy, Architecture, Photography 


\section{ARCHITECTURAL PHOTOGRAPHY AS A RESUMPTION. REFLECTIONS ON THE MEDIUM}

Written by Mariela Apollonio

A large number of researchers and theorists agree that the inseparable link between photography, architecture and the mass media, as we know it today, came about with the emergence of the Modern Movement or International Style in architecture. During this period, and for the first time, architectural firms began to think about their buildings from a photographical perspective. They became aware of its great potential for architecture in the media and began to take their visual representation and dissemination into consideration when designing their buildings.

One of the most significant things to arise from this time of confluence between photography, architecture and the mass media is what is today known as architectural photography. It came into being as a way of doing things, as a discipline with its own rules, which I will refer to as the 'image mechanism'. It is an image, which exists within a world of general agreements or consensuses and fulfills a function. The circle that forms this image mechanism can be said to have survived until the present and is made up of the architect, photographer and specialist publication and their resultant interactions. It is an image though which architecture must be represented and displayed in order to take on meaning as a medium for communication.

\section{The Image Mechanism}

The image mechanism is an authorless image; in other words, it is a flat image in form and function and is integrated into the structure of a system. It necessitates a camera and a mechanism for producing clear, transparent, inert images, more particularly bereft of any subjectivity or positioning. Its aims are explicit, linear and predictable, and are governed by the same rules that govern the interests of the mass media or of advertising. It is a wrapping for which the photographed subject is of little concern, given that its processing is purely superficial.

Architecture does not matter to the image mechanism; its main aim is to resemble other image mechanisms. According to David Campany, the photography of a building can isolate, define, interpret, exaggerate or even invent its cultural value. "The cultural value of buildings is what we call architecture, and it is inseparable from photography"'. Having reached this point, one must wonder whether the values of the image mechanism, in the way they have been conceived since the Modern Movement until the present day, continue to represent the cultural value we wish to project using architecture, and what we ultimately understand to be architecture.

\footnotetext{
1 David Campany: La arquitectura através de la fotografía: Documento, publicidad, crónica, arte, p.27. Catalogue of the Construyendo Mundos (Constructing Worlds) exhibition held at the ICO Museum, Madrid. Published by: Fundación ICO, La Fábrica, 2015.
}

2 RE-INTERPRETING KIDDER SMITH'S ITALY BUILDS: CROSSOVERS BETWEEN PHOTOGRAPHY AND ARCHITECTURE. 

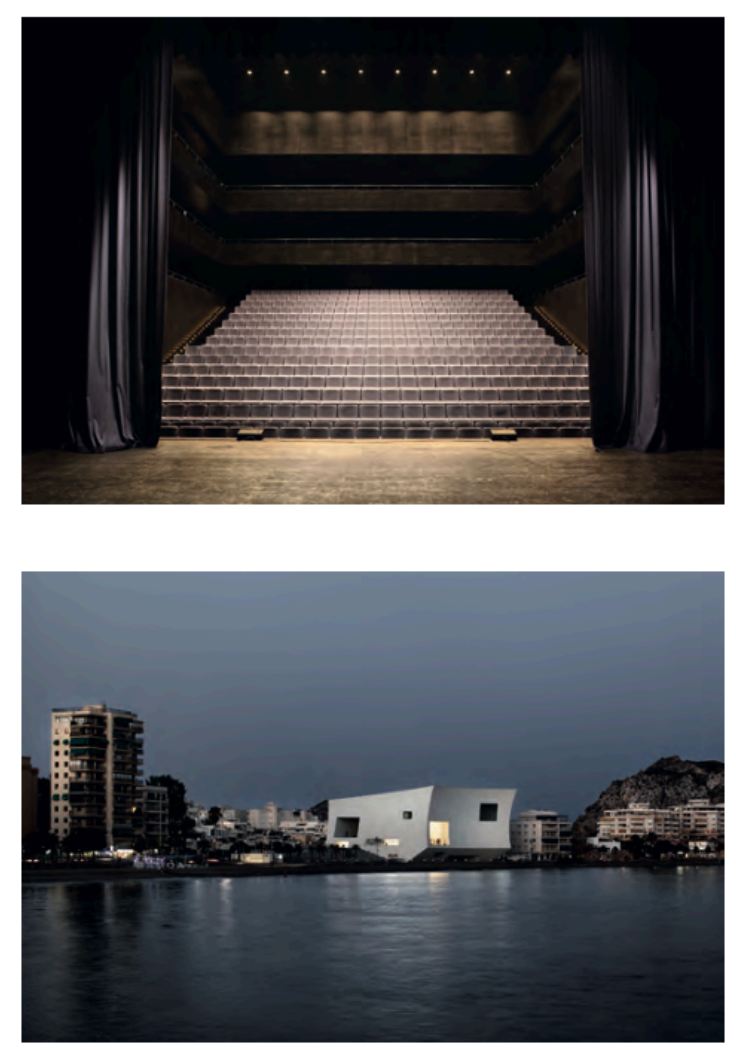

MARIELA APOLLONIO

Aguilas 3

The current state of play in architectural photography is the image mechanism at its peak. The mass media dominates architectural projects, architects and the way of displaying or photographing them. The architectural photographer has become a producer of advertising images to enhance the photographic appeal of the building, not necessarily its complexity or significance. Architectural photography, following in the steps of computer rendering, has created a world of simulations inherent to it. It has turned into a 'different' architecture with which the architecture of phenomena and materiality cannot compete. Does the image mechanism represent the cultural value that we want to project of architecture today? Would it be possible to consider an architectural photograph beyond the bounds of this inherited system?

Hysteresis is a term used in physics to describe the tendency of a material to preserve its form and properties in the absence of the stimulus by which it was produced. It is the quality of certain materials, such as plastic, when pressure is applied, to take on a new form in the absence of the force that produced this effect. Using this term as a metaphor, I would hazard to say that architectural photography retains a residual magnetism that enables it to continue to exist in a state of 'photographic hysteresis', despite the changes that have taken place in architecture.

The architectural image demands a paradigm shift, a structural change that breaks down its hermetic and inherited triangle. It demands other forms of representation, other media in which to develop; it needs new allies to support it. I would go so far as to say that architectural photography must undergo a process of self-reflection and be freed from its photographic 
hysteresis if it is to be more than a utilitarian and subservient medium. A process of reflection of the medium through which the characteristics of its actual specificity, the thing that defines it as such, can be recognised. In the new design for this 'image', the subject matter will continue to be architecture, although its aim will no longer be promotional interests but its own set of questions.

Architectural photography must aspire to become 'a concept in itself' in order to become an extension of the ideas of the architect and to interpret, through architecture, the cultural value of a society, or rather, of as many forms of architecture and societies that exist.

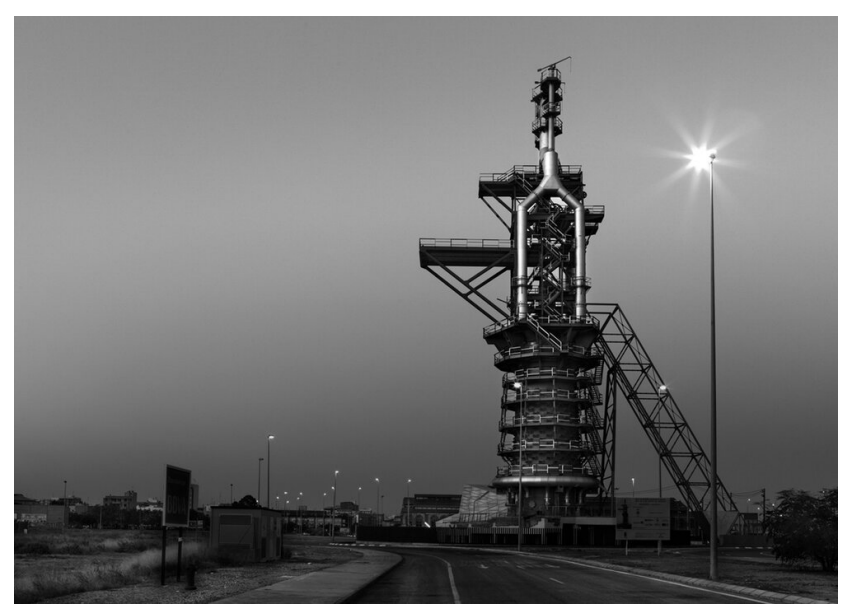

MARIELA APOLLONIO

Blace Furnace Sagunto, Spain.

Gradoli \& Sanz, Luis Francisco Herrero Architects, 2011

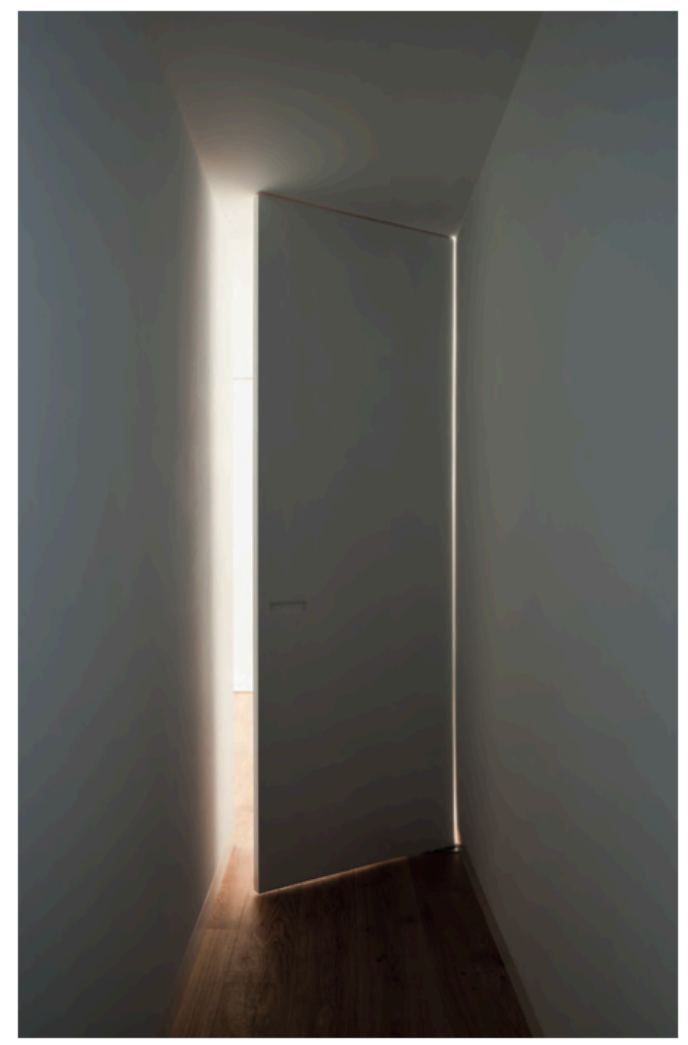


MARIELA APOLLONIO

Penthouse in Valencia, Spain. DG architect, 2014
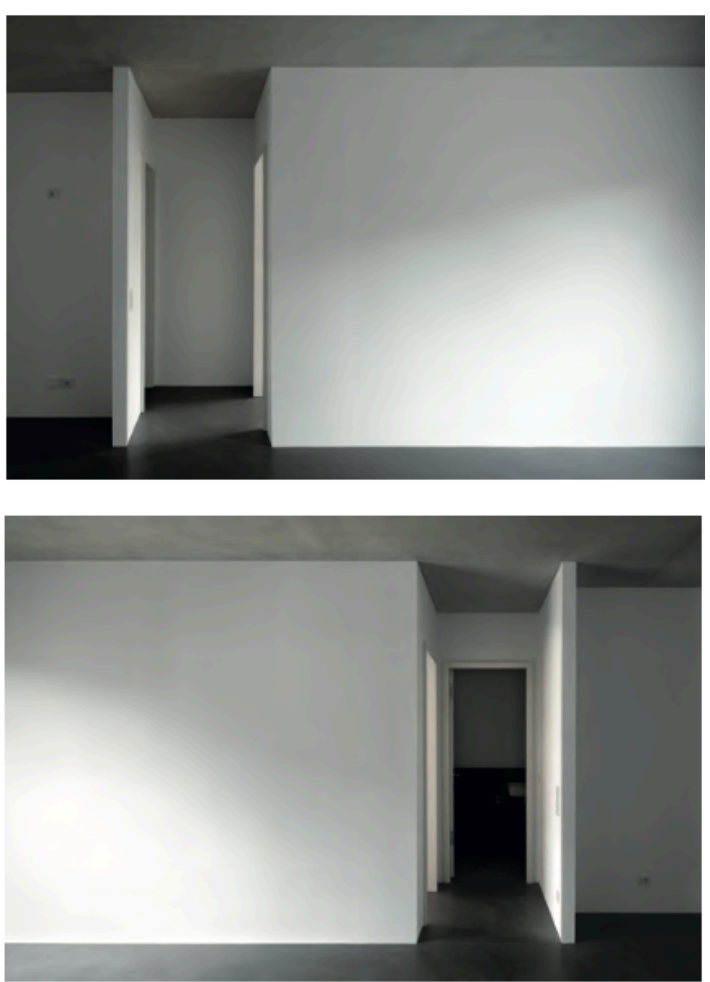

MARIELA APOLLONIO

Kiefholzstrasse, Berlin, Germany

Marius Schliekmann Architekten, 2014 

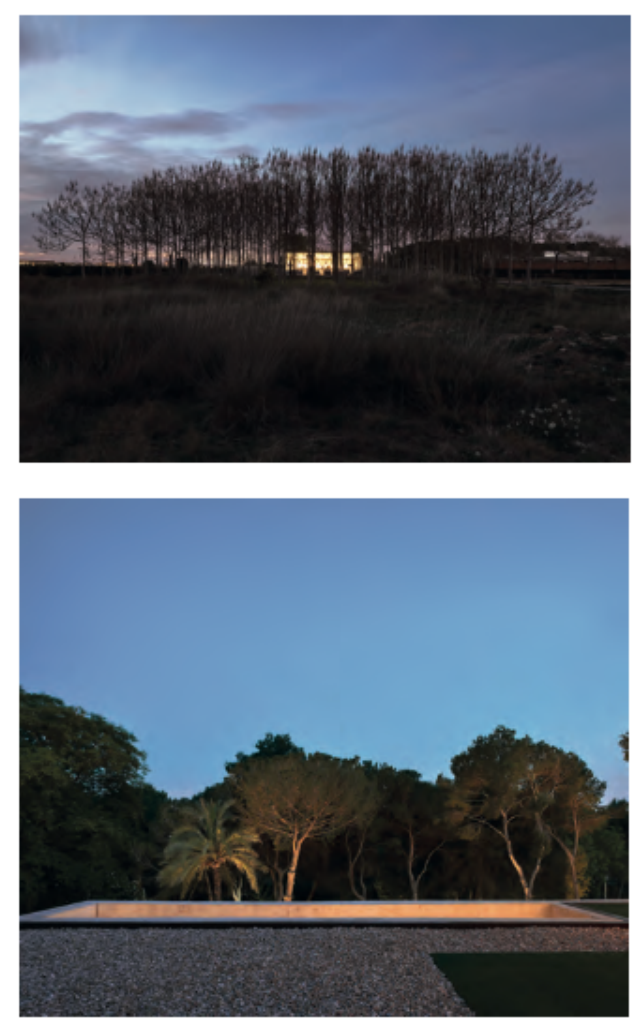

MARIELA APOLLONIO

Escola Gavina in Picanya, València.

Arturo Sanz \& Carmel Gradoli, Carmen Martínez Gregori architects, 2015

La Pinada House in Valencia, Spain.

Ramón Esteve Studio, 2017

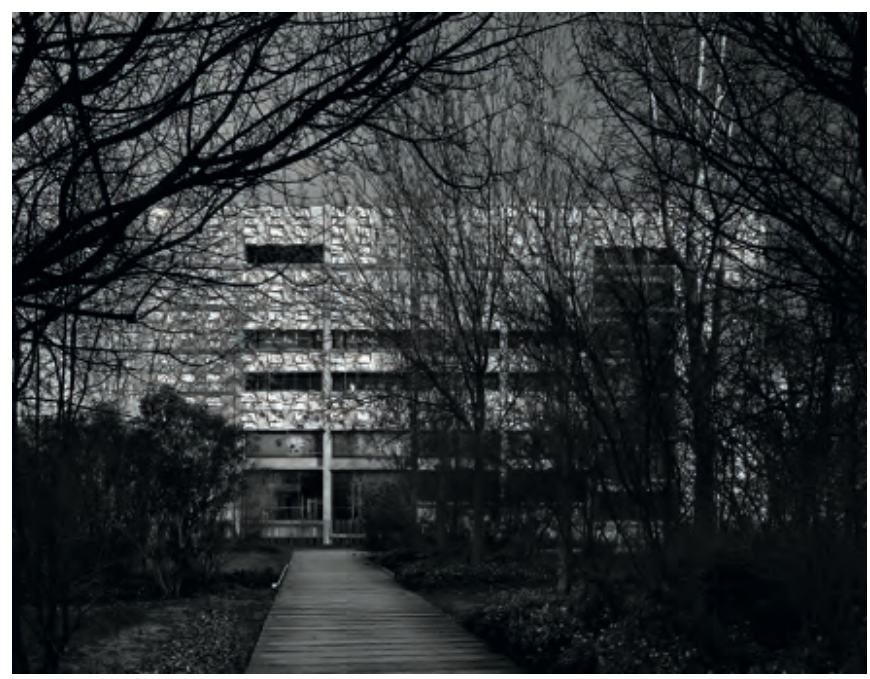

MARIELA APOLLONIO

Espai Rambleta Auditorium, Valencia, Spain. Sanz \& Gradolí Arquitects, 2013 


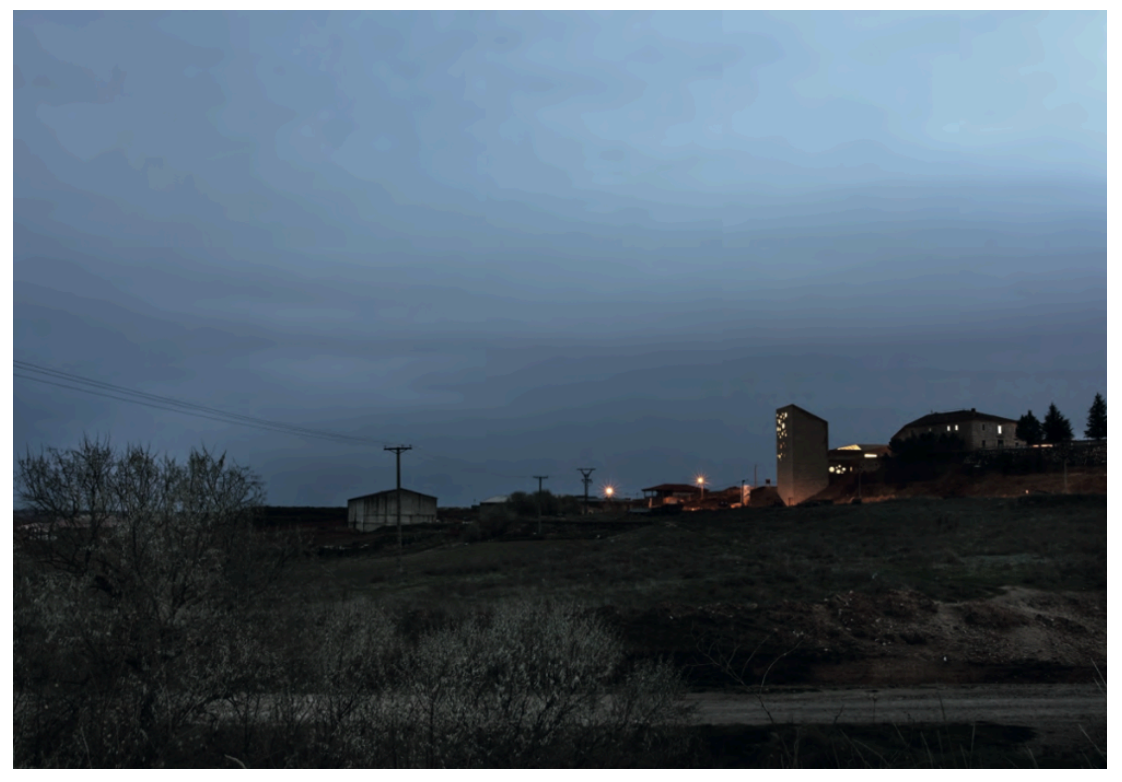

MARIELA APOLLONIO

Ribera del Duero Headquarters Roa, Spain. Barozzi Veiga Architects, 2010 